\title{
BMJ Open Long-term experiences of Norwegian live kidney donors: qualitative in-depth interviews
}

\author{
Käthe B Meyer, ${ }^{1,2}$ Ida Torunn Bjørk, ${ }^{3}$ Astrid Klopstad Wahl, ${ }^{4}$ Annette Lennerling, ${ }^{5}$ \\ Marit Helen Andersen ${ }^{1}$
}

To cite: Meyer KB, Bjørk IT, Wahl AK, et al. Long-term experiences of Norwegian live kidney donors: qualitative indepth interviews. BMJ Open 2017;7:e014072.

doi:10.1136/bmjopen-2016014072

- Prepublication history for this paper is available online. To view these files please visit the journal online (http://dx.doi.org/10.1136/ bmjopen-2016-014072).

Received 29 August 2016 Revised 8 November 2016 Accepted 19 December 2016

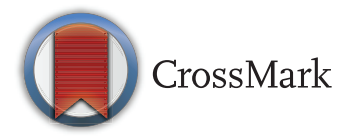

\footnotetext{
${ }^{1}$ Department of Transplantation, Oslo University Hospital, Rikshospitalet, Norway ${ }^{2}$ Institute of Clinical Medicine University of Oslo, Oslo, Norway

${ }^{3}$ Department of Nursing Science, University of Oslo, Oslo, Norway

${ }^{4}$ Department of Health Science, University of Oslo, Oslo, Norway

${ }^{5}$ Department of

Transplantation, Sahlgrenska University Hospital, Gothenburg, Sweden
}

Correspondence to Käthe B Meyer; kathe.meyer@ous-hf.no

\section{ABSTRACT}

Objective: Live kidney donation is generally viewed as a welcome treatment option for severe kidney disease. However, there is a disparity in the body of research on donor experiences and postdonation outcome, and lack of knowledge on long-term consequences described by the donors. This study was conducted to provide insight into donors' subjective meanings and interpretation of their experiences $\sim 10$ years after donation.

Design: Qualitative explorative in-depth interviews. The sampling strategy employed maximum variation. Setting Oslo University Hospital is the national centre for organ transplantation and donation in Norway, and there are 26 local nephrology centres.

Participants: 16 donors representing all parts of Norway who donated a kidney in 2001-2004 participated in the study. The interviews were analysed using an interpretative approach.

Results: The analysis resulted in 4 main themes; the recipient outcome justified long-term experiences, family dynamics-tension still under the surface, ambivalence-healthy versus the need for regular follow-up, and life must go on. These themes reflect the complexity of live kidney donation, which fluctuated from positive experiences such as pride and feeling privileged to adverse experiences such as altered family relationships or reduced health.

Conclusions: Live kidney donors seemed to possess resilient qualities that enabled them to address the long-term consequences of donation. The challenge is to provide more uniform information about long-term consequences. In future research, resilient qualities could be a topic to explore in live donation.

\section{BACKGROUND}

Owing to the increasing need for kidney transplantation and the superior results of live transplantation, live kidney donors (LKDs) are frequently used. ${ }^{1}$ However, the increase in LKD use has slowed with no clear explanation in Norway and other countries. ${ }^{2}$

In previous research, the relationship to the recipient, expectations related to one's

\section{Strengths and limitations of this study}

- Data were collected through in-depth interviews and reflects actual experiences.

- The qualitative approach provided in-depth understanding of experiences and first-person perspectives in the long term after kidney donation.

- The study was conducted by an experienced team of researchers who covered different perspectives in the research method and in the clinical field.

- None of the donors were younger than 30 years old at the time of the donation and long-term experiences in young adults may be different than older adults' experiences.

- The study was performed in Norway and experiences may differ in another geographical setting.

own or recipient outcome, and perceived support have been associated with the donor's health outcomes. ${ }^{3-12}$ Concern about the recipient's health may influence the donor's decision, ${ }^{13}{ }^{14}$ and the outcome of the transplantation may have an impact on the donor's life and health. ${ }^{7} \quad 8 \quad 15$ Postdonation experiences vary from disturbed family hierarchies and failed relationships with the recipient ${ }^{16}$ to support from the recipient and other family members. ${ }^{11}$ Explaining the disparity in LKD experiences in the body of research is challenging, and resilience has recently been introduced in live donation as a possible protective factor. ${ }^{17}{ }^{18}$ Resilience can be defined as a matter of coping or adapting to life events. ${ }^{19}$

Qualitative research can provide in-depth understanding of experiences and firstperson perspectives that surveys cannot capture. ${ }^{20}$ However, qualitative research on LKDs varies in methods. Most of the qualitative research represents short-term follow-up, ${ }^{8} 11 \quad 1416$ while other studies have shown variation in follow-up time ranging from $<12$ months to 29 years. $^{12} 15$ Our 
current knowledge indicates that live kidney donation is complex, and little is known about donors' long-term experiences. To provide information and adapt follow-up care to future donors, a need exists for more knowledge of the donors' unique experiences from a long-term perspective. The present study is part of a larger mixed-methods study in which a cross-sectional survey on self-reported health outcomes ${ }^{7}$ is the first component, and this explorative in-depth interview study is the second component. Hence, the aim of our paper is to provide insight into the donors' experiences almost 10 years after donation.

\section{METHODS}

Design

Explorative in-depth interviews were performed to provide insight into the donors' subjective meanings and interpretations of their experiences. ${ }^{21} 22$

\section{Setting}

Oslo University Hospital is the national centre for organ transplantation and donation in Norway. The donor work-up and follow-up is performed at 26 local nephrology centres situated in four health regions.

\section{Participants}

The purposeful sample consisted of 16 LKDs donating at Oslo University Hospital, who had participated in the cross-sectional survey. The donors' postdonation follow-up was performed at local hospitals representing all parts of Norway. We conducted maximum variation sampling from the larger sample based on self-reported health outcome, age, gender and relationship to the recipients, to select donors to be invited to participate. However, it was not possible to reach every donor demographic, and none of the donors in the sampling were younger than 30 years or older than 60 years at donation time. Inclusion of participants was concluded when no new information was provided. ${ }^{22}$ A purposeful sample facilitates obtaining information-rich participants who can provide both insight and depth. Additionally, a maximum variation sampling strategy provides an opportunity to compile central themes across various experiences. ${ }^{22}$ Using this method we could obtain in-depth information about the experience of being a live donor in the long term.

\section{Interviews}

A semistructured interview guide was prepared to ensure that relevant topics were discussed. The topics were based on clinical experiences, previous research and responses on the cross-sectional survey. ${ }^{7}$ They included the importance of donation with regard to possible changes in the donor's life, the relationship with the recipient, the donor's contact with the healthcare system postdonation, the recipient outcome and the donor's expectations of the donation. The informants' long-term experiences were highlighted during the interview. Open-ended questions such as: 'Could you please describe how your life is today?' and 'Could you please tell me what kind of significance the donation have had for your life?', elicited narratives in the donor's own words. The interviews were performed by the first and the last authors (KBM and MHA). Both have clinical experience with LKD, but neither have a present healthcare relationship with any of the participants. The interviews were conducted in the period between spring 2014 and spring 2015. They took place in the participant's home, workplace or in a hospital, and lasted between 25 and $65 \mathrm{~min}$.

\section{Data analysis}

The narratives were transcribed verbatim either by KBM or by an assistant. The text was analysed through a hermeneutical approach using Kvale and Brinkmann's ${ }^{23}$ three contexts of analysis of qualitative data, and was focused on condensation and interpretation of the meaning. A hermeneutical approach provides an opportunity to understand live donation in the context of the donors' lives in a long-term perspective. Examples from the analysis are shown in table 1 .

KBM conducted the first steps of the analysis. To obtain an overall impression, the transcripts and reflection notes from each interview were read several times. The first context of the analysis comprised a rephrased condensation of the informant's own views. In the next context the elucidated meanings were interpreted by moving back and forth between the data and the researchers' perspectives, and the meanings were merged into broader categories. To make the study as trustworthy as possible the categories were first discussed by KBM, MHA and ITB. Second, all co-authors discussed and agreed on the categories. Additionally, the findings are illustrated with quotations from the interviews to show our interpretation of the persons' experiences and make the interpretations clear, credible, transferable and confirmable. Finally the categories were investigated in a theoretical context as presented in the Discussion section. ${ }^{23}$

\section{Ethical considerations}

An invitation letter was sent to eligible candidates that included information about the study, confidentiality and the possibility to withdraw from the study at any time. KBM contacted the donors who consented to participate and choose a suitable time and place for the interview.

\section{RESULTS}

Invitation to participate in the interviews was sent to 22 donors, and 16 donors accepted. Donor characteristics are shown in table 2. As the sample was small and the Norwegian living kidney donors are easily recognisable, the table displays merely gender, relationship with the 
Table 1 Examples from the analysis

\begin{tabular}{|c|c|c|}
\hline Natural meaning unit, statements & Subthemes & Theme \\
\hline $\begin{array}{l}\text { It was not intentionally, I understand that, but my } \\
\text { stomach is damaged for life. I had a much better } \\
\text { life before this, but my sister is fine, the kidney } \\
\text { works well. I think I had given her kidney again. } \\
\text { She considers I have given a huge gift, I would say. } \\
\text { Thus I believe she felt I was intimate and yes, we } \\
\text { have had good relations. I have felt she was very } \\
\text { grateful. Even if the kidney doesn't work anymore, } \\
\text { you may say it was many years she had a better } \\
\text { life, by receiving a kidney. }\end{array}$ & $\begin{array}{l}\text { Experiencing that the recipient had a good } \\
\text { life compensated the donor's own adverse } \\
\text { experiences. } \\
\text { The donation triggers gratefulness from } \\
\text { the recipient and his/her family. }\end{array}$ & $\begin{array}{l}\text { The recipient outcome } \\
\text { justified long-term } \\
\text { experiences. }\end{array}$ \\
\hline
\end{tabular}

recipient and geographical area in order to maintain confidentiality and the donors' anonymity. The youngest donor was 42 years old and the oldest was 66 years at the time of the interview. The time since donation varied between 10 and 14 years. The donors' experiences were categorised into the following four main themes: the recipient outcome justified long-term experiences, family dynamics-tension still under the surface, ambivalence-healthy versus the need for regular follow-up, and life must go on.

\section{The recipient outcome justified long-term experiences}

A major theme was that the donation became meaningful because it was strongly motivated by the recipient's prospect of living a good and active life with his/her family. Even if the benefit of the transplantation was less than anticipated, the donors were still confident about their decision. One of the donors reflected on having been the one to decide between life and death: "If I may be dramatic; I had the opportunity to give my sister a chance to live. She wasn't going to die. Clearly, she had to receive a part of me" (F, 6). Even now the donors assumed that live donation was the recipients' only possibility to avoid dialysis and live a better life due to the lack of deceased organs.

The delight in seeing the recipient living an active and normal life compensated for the donors' own

\begin{tabular}{lr} 
Table 2 Donor characteristics & N \\
\hline Gender & 6 \\
\hline Male & 10 \\
Female & \\
Relation to recipient & 6 \\
Parent & 6 \\
Sibling & 3 \\
Offspring & 1 \\
Spouse & 2 \\
Health-region affiliation & 2 \\
Northern Norway & 1 \\
Central Norway & 11 \\
Western Norway & \\
South-Eastern Norway & \\
\hline
\end{tabular}

adverse experiences. Gratitude from the recipient and his/her family and the continued respect that they received from others contributed to a sense of pride and being privileged. However, an underlying anxiety existed regarding the recipient's well-being and the graft survival even if none of the donors claimed to feel responsible for the recipient's current health. A male informant said: "You are cautious when you know he is going to see the doctor. I wonder if it is the kidney, is the time running out? So I am on guard" (M, 9). The anxiety was associated with the assumption of limited graft survival time and the recipient's possibility of receiving a new graft.

Being a donor was not merely a positive experience, and losing contact with the recipient was bothersome. One sibling tried to excuse a brother who had cut-off all contact:

My brother and I have no connection after the donation. I figure this is quite rare. We lost touch completely. I believe he feels so grateful that he rejects me. We used to be very close, but after the donation it is the opposite. (F, 3)

Donors who experienced altered relationships or changes in their own health had decided to put the adverse experiences aside and continue onward. They wanted to focus on the positive experiences. Another donor explained how long-term complications associated with the donor nephrectomy had implications for family life:

Fortunately, my husband is very understanding. Otherwise, I am not sure he would have been by my side today. My health has deteriorated in all respects.

However, eventually it will go well, it will... (F, 13)

Although the donation had current physical and psychosocial consequences, a need existed to be optimistic and confident in regaining health. Others had experienced resistance in their own families or negative reactions to the decision to be a donor. However, they were determined to stand by their decision, and were certain that donation had been the appropriate choice. 
Family dynamics-tension still under the surface

For some, the donation was experienced as a watershed that did not concern only the donor and the recipient, but the whole family. "It was a tough time for me and my husband. Though, it might have been easier for me; I was allowed to do something. It was a hard-hitting marital event" (F, 10). In hindsight, the donor realised that it might have been easier to be the one who could actively be of help than being unable to take action.

While donation still was the obvious choice for some donors, others had felt an implicit or explicit pressure.

I decided to be the first one to be tested because I had the impression that my brother thought surgery and hospital was a bit scary. Afterwards we haven't mentioned it.

I do love my brother, you know. (F, 14)

When the pressure was implicit it seemed as if the donor had taken responsibility for the whole family and did not want to reconsider. Then again, explicit pressure appeared to have made the decision into a difficult process. One sibling explained the negotiation as follows: "I thought it was unfair, I was the youngest, the oldest brother could be the donor, but my older sister claimed; it was only you who offered to donate" (F, 11). The process continued to affect interpersonal relationships within the families. Another sibling described how the process had altered family relations: "The dispute may still be there, in the back of my mind, it may never disappear $100 \%$. There was a disappointment related to the way things were said" (M, 16). The siblings' duplicity and the feeling of betrayal that emerged during the donation process caused a breach in their relationships that might never be fully mended.

\section{Ambivalence-healthy versus the need for regular follow-up}

Long-term follow-up safeguarded the donors' need to monitor their own health and to be valued for the good deed. "The doctors monitor my health. I am at a medical follow-up every second year; the creatinine increases. I understand it's nothing hazardous, I don't worry" (M, 2). The donors relied on the physicians' abilities to monitor their health and medical risks. The medical follow-up was appreciated and viewed as a warranty by those who had continued to visit the nephrologist. When the hospitals guaranteed follow-up on a regular basis they felt secure and valuable.

Looking back, donors deliberated about the predonation reassurances of the safety of the donation. Before donation, they avoided reflecting about the consequences and relied on the medical assessment. Afterwards, they took care of themselves, tried to avoid anything that might be harmful, and were protective of the remaining kidney. Although most of the donors denied that the nephrectomy had been harmful, an underlying insecurity was present.
Contradictory opinions among health professionals caused uncertainty about the value of the medical follow-up, as shown by a female informant:

I asked why, what is the point when I am healthy? That is how I feel, but then I think about what they said in the beginning; donors stay healthy because of the medical follow-up. They might uncover other things, so maybe it's wise. I don't worry about the kidney, but it could be high blood pressure or something. (F, 14)

Initially, the donors were guaranteed to be in good health; however, they were encouraged to continue their medical follow-up. The practice of follow-up consultation differed, and some of the donors perceived the consultations as shallow. The focus was on kidney parameters, and not on the donor's well-being. "All is well, nevertheless, it feels good to have that chat; yes, your sister is doing well, of course I know that, but it is okay to receive that feed-back, the follow-up is okay" $(\mathrm{F}, 6)$. A more comprehensive follow-up where the donor could discuss worries about their own health or the recipient's health was valued.

\section{Life must go on}

When time had passed the donation was no longer the most important event in life. The focus on the donation waned and everyday life continued. Several claimed that being left with one kidney did not have any effect on their health or how they lived their lives. A male donor said:

My choice has been not to look for problems. I haven't had any complications, and I never wanted to think I had any. It hasn't had a negative effect on my everyday life. Have to have a positive view. I couldn't do it any other way. (M, 16)

To move forward in life, it was important to look forward and not focus on changes or problems that followed the donation.

Quite a few donors underlined the sense of pride and the admiration that they still perceived from others. "I don't know whether I am happier, but yes, I don't mind the acknowledgement I sense once in a while" (F, 11). Nevertheless, the improved quality of life predicted during the work-up before the donation seemed to be over-rated. Although many of the donors still felt attached to the recipient, donors and recipients did not see each other as often as they did shortly after donation. One of the donors reflected on how the significance of the donation waned with time:

Looking back, we were never in doubt; when she received the kidney she would become well. Done! The first years we used to celebrate, one year, five years, but now, it's kind of forgotten. (F, 14)

Several of the donors highlighted that their recipients showed their gratitude by honouring the day of the 
donation by a phone call or a gift to the donor. Some of the donors appreciated the gesture while others argued that the significance of the donation was minor. It was something they had done more than 10 years ago and had left behind.

\section{DISCUSSION}

The results of our study illustrate how donors' experiences fluctuated between pride and being privileged versus altered family relations and reduced health. However, the recipients' potential for improved health seemed to supersede the donors' own long-term consequences and justified donation even when the recipient outcome was not as good as anticipated. According to the metatheory of resilience and resiliency, ${ }^{19}$ live kidney donation can be seen as a life event. As we understand the model, a donor's resilient qualities may be strengthened when the donor is able to choose the outcome of the life event. The donors made their own decision to donate and decided that no matter what happened they would live with the consequences. The risk and consequences of the donor nephrectomy became acceptable due to prospect of improvement of the recipient's life. This may be understood as resilient reintegration; the donor adapted to the situation in mind, body and spirit. Consistent with previous research, ${ }^{6} 91314$ the donors' decision was motivated by a wish to help, altruism and personal benefit, which is part of the motivational force in resilience. ${ }^{19}$ The motivational force seems to persist and may elucidate how the recipient outcome of the donation compensated for the long-term consequences.

The sense of pride, as a result of perceived respect and gratefulness, corresponds with the results from our previous report on long-term self-reported health, ${ }^{7}$ perceived recognition from family and friends was significantly associated with quality of life. In another study, ${ }^{17}$ extroversion was correlated with postdonation growth, and the authors advocated that social support may be important in positive coping and growth after donation. This again can provide increased self-esteem and purpose in life which is part of resilience. ${ }^{17} 19$

Donors with adverse experiences had chosen a positive view and they still had hopes to regain health or improve relationships. To cope with the disappointment when the recipient discontinued all contact, the recipient's detachment was rationalised as unexpressed gratefulness. Hope, optimism and forgiveness have been identified as resilient qualities. ${ }^{19}$ The donors in our study seemed to employ these qualities. It looks as if the donation contributed to a lasting perception of purpose in life, self-esteem and personal growth that counterbalanced negative consequences.

The impaired relationships that were evident in some families and especially between siblings are consistent with the result in a Swedish cross-sectional study. Lennerling $e t a t^{6}$ found that spouses' motivation was to improve the situation for the whole family, while siblings had a moral obligation to donate. The obligation may cause a moral incontinence, a combination between external and internal moral constraints. ${ }^{24}$ The persistent tension might be a result of inequality between the siblings; the sibling who took responsibility responded to the moral obligation while the siblings who did not donate might not be able to respond to internal and external constraints. The inequality may lead to a breach in the relationship between the donor, the nondonor siblings and the recipient.

Another key finding was the ambivalence on medical follow-up. This may be a result of the predonation reassurances about the low medical risks and contradictory attitudes among health professionals regarding the need for follow-up. However, recent research on long-term risks indicates an increased medical risk after kidney donation and an increased risk during pregnancy. ${ }^{25-27}$ Garg and colleagues $^{27}$ revealed a higher incidence of gestational hypertension and pre-eclampsia in female kidney donors compared with non-donors. Furthermore, we revealed an underlying anxiety regarding the remaining kidney. Conversely, Rodrigue $e t a t^{28}$ found non-donors to be more concerned about kidney damage than LKDs. They concluded that the donors were well informed about the risks. Nevertheless, a need to adjust predonation information might exist. In addition, it might be beneficial if longterm follow-up was a matter of discussion among transplant professionals to ensure a more consistent attitude. The donors in our study had different experiences and expectations of the medical consultations. The consultations could be an arena for the donors to discuss their own health and concerns for the recipient. However, according to the confidentiality oath, it may not be advisable to provide information about the recipient's health.

In the long term, the significance of the donation waned and the donors continued with their lives. It is easy to comprehend this progression; the donors are healthy persons who for a period of time were affected by donating a kidney, and now the majority have returned to their daily life. Consistent with our qualitative data, several studies ${ }^{3}{ }^{10}$ using a quantitative approach have documented similar findings.

We wanted to explore long-term experiences and used a maximum variation sampling strategy based on selfreported health outcomes, gender, age and relationship to the recipient. In our previous report, ${ }^{7}$ donors who regretted donation scored much higher than average on fatigue. A significant association was also present between fatigue and whether the recipient was alive or dead. None of the participants in this study regretted their decision, and all the recipients were still alive. This might be a limitation as we could not explore how the recipient's status could influence long-term experience. However, for some of the donors in our study, the result of donation was not as anticipated; the recipient was back on dialysis or had other adverse outcomes. Another limitation might be that all our donors were related to the recipient as non-directed donation is not an option in Norway. 
In conclusion, LKDs seem to possess resilient qualities that enable them to address both expected and unexpected long-term consequences. The challenge is to provide more uniform information about long-term consequences. It might be beneficial to facilitate an atmosphere for expressing both pride and worries. In our study, we have provided a scientific contribution to understanding how resilience might illuminate LKD experiences. In future research, resilience and resilient qualities could be one of several topics to explore regarding live donation.

Acknowledgements The authors thank Torill Løken for transcribing the interviews and, in particular, the donors who participated.

Contributors KBM and MHA participated in collecting and analysing the data, and writing and editing the manuscript. ITB, AKW and AL participated in analysing the data and editing the manuscript.

Funding This work was supported by the Norwegian Health Authority South-East region.

Competing interests None declared.

Ethics approval The study was approved by the Regional Medical Research Committee for Health South-East of Norway (2011/2595 D) and the hospital's data protection officer.

Provenance and peer review Not commissioned; externally peer reviewed.

Data sharing statement No additional data are available.

Open Access This is an Open Access article distributed in accordance with the Creative Commons Attribution Non Commercial (CC BY-NC 4.0) license, which permits others to distribute, remix, adapt, build upon this work noncommercially, and license their derivative works on different terms, provided the original work is properly cited and the use is non-commercial. See: http:// creativecommons.org/licenses/by-nc/4.0/

\section{REFERENCES}

1. Horvat LD, Shariff SZ, Garg AX. Donor nephrectomy outcomes research $\mathrm{N}$. Global trends in the rates of living kidney donation. Kidney Int 2009;75:1088-98.

2. Reese PP, Boudville N, Garg AX. Living kidney donation: outcomes, ethics, and uncertainty. Lancet 2015;385:2003-13.

3. Gross CR, Messersmith EE, Hong BA, et al. Health-related quality of life in kidney donors from the last five decades: results from the RELIVE study. Am J Transplant 2013;13:2924-34.

4. Watson JM, Behnke MK, Fabrizio MD, et al. Recipient graft failure or death impact on living kidney donor quality of life based on the living organ donor network database. J Endourol 2013;27:1525-9.

5. Mjøen G, Stavem K, Westlie L, et al. Quality of life in kidney donors. Am J Transplant 2011;11:1315-19.
6. Lennerling A, Qureshi AR, Fehrman-Ekholm I. Spouses who donate seem to be the winners-a questionnaire study of kidney donors long-term. Open J Nephrol 2012;2:44-8.

7. Meyer K, Wahl AK, Bj, et al. Long-term, self reported health outcomes in kidney donors. BMC Nephrol 2016;17:8.

8. Andersen $\mathrm{MH}$, Bruserud F, Mathisen L, et al. Follow-up interviews of 12 living kidney donors one yr after open donor nephrectomy. Clin Transplant 2007;21:702-9.

9. Lennerling A, Forsberg A, Meyer K, et al. Motives for becoming a living kidney donor. Nephrol Dial Transplant 2004;19:1600-5.

10. Clemens K, Boudville N, Dew MA, et al. The long-term quality of life of living kidney donors: a multicenter cohort study. Am J Transplant 2011;11:463-9.

11. Gill P. Stressors and coping mechanisms in live-related renal transplantation. J Clin Nurs 2012;21:1622-31.

12. Brown JB, Karley ML, Boudville N, et al. Living kidney donors' experiences with the health care system. Soc Work Health Care 2008;46:53-68.

13. McGrath $P$, Pun $P$, Holewa $H$. Decision-making for living kidney donors: an instinctual response to suffering and death. Mortality 2012;17:201-20.

14. Agerskov $\mathrm{H}$, Bistrup $\mathrm{C}$, Ludvigsen MS, et al. Living kidney donation: considerations and decision-making. J Ren Care 2014;40:88-95

15. Williams AM, Colefax L, O'Driscoll CT, et al. An exploration of experiences of living renal donors following donation. Nephrol Nurs $J$ 2009;36:423-7.

16. Langenbach M, Stippel A, Stippel D. Kidney donors' quality of life and subjective evaluation at 2 years after donation. Transplant Proc 2009;41:2512-14

17. Rudow DL, lacoviello BM, Charney D. Resilience and personality traits among living liver and kidney donors. Prog Transplant 2014;24:82-90.

18. Erim $Y$, Kahraman $Y$, Vitinius $F$, et al. Resilience and quality of life in 161 living kidney donors before nephrectomy and in the aftermath of donation: a naturalistic single center study. BMC Nephrol 2015;16:164.

19. Richardson GE. The metatheory of resilience and resiliency. $J$ Clin Psychol 2002;58:307-21.

20. Tong A, Chapman JR, Israni A, et al. Qualitative research in organ transplantation: recent contributions to clinical care and policy. Am J Transplant 2013;13:1390-9.

21. Morse JM, Niehaus L. Mixed method design: principles and procedures. Walnut Creek, California: Left Coast Press, 2009.

22. Patton MQ. Qualitative research \& evaluation methods. 3rd edn. Thousand Oaks, California: SAGE Publications, 2002:598.

23. Kvale S, Brinkmann S. Interviews: learning the craft of qualitative research interviewing. 2nd edn. Thousand Oaks, California: SAGE publications, 2009:353.

24. Begley A, Piggott S. Exploring moral distress in potential sibling stem cell donors. Nurs Ethics 2013;20:178-88.

25. Mjoen G, Hallan S, Hartmann A, et al. Long-term risks for kidney donors. Kidney Int 2014;86:162-7.

26. Muzaale AD, Massie AB, Wang MC, et al. Risk of end-stage renal disease following live kidney donation. JAMA 2014;311:579-86.

27. Garg AX, Nevis IF, McArthur E, et al. Gestational hypertension and preeclampsia in living kidney donors. $N$ Engl $J$ Med 2015;372:124-33.

28. Rodrigue JR, Fleishman A, Vishnevsky T, et al. Development and validation of a questionnaire to assess fear of kidney failure following living donation. Transpl Int 2014;27:570-5. 